\title{
Role of Chemotherapy in Advanced Gastric Cancer: Review from a Latin American Perspective
}

\author{
Marcelo Garrido $^{{ }^{*}}$, Paula Jimenez-Fonseca², Maria Pilar Solis ${ }^{2}$, Alberto Carmona-Bayonas ${ }^{3}$, \\ Sebastian Mondaca1, Bruno Nervi1, Jorge Madrid1 \\ ${ }^{1}$ Cancer Center, Hematology-Oncology Department, Pontifical Catholic University, Santiago, Chile \\ ${ }^{2}$ Medical Oncology, Digestive Tumors, University Central Asturias Hospital, Oviedo, Spain \\ ${ }^{3}$ Medical Oncology, Digestive Tumors, Morales Meseguer Hospital, Murcia, Spain \\ Email: "mgarrido@med.puc.cl
}

Received 7 October 2015; accepted 1 January 2016; published 4 January 2016

Copyright (C) 2016 by authors and Scientific Research Publishing Inc.

This work is licensed under the Creative Commons Attribution International License (CC BY).

http://creativecommons.org/licenses/by/4.0/

(c) (i) Open Access

\begin{abstract}
Gastric cancer (GC) is the fourth most common neoplasm and the second leading cause of cancer-related death worldwide. In Latin America (LA), the burden of this disease is higher and is the leading cause of cancer death in some countries. Chemotherapy is the standard treatment for advanced-stage GC. However, the best regimen for specific populations, such as LA, is as yet unknown. Cisplatin and fluoropyrimidine continue to be the standard of care in light of the findings of phase III studies, while docetaxel, cisplatin, and 5-fluorouracil (5-FU) are alternatives for patients with suitable overall health. Oxaliplatin or irinotecan with fluoropyrimidine can also be used in elderly patients who are not candidates for cisplatin, or have a limited performance status. This review examines studies conducted in LA. Patients from LA are under-represented in multicenter trials of chemotherapy and targeted therapies. The major challenges currently lie in implementing strategies in which patients are selected on the basis of regional, racial or molecular characteristics, to consider the molecular subtype of GC for enrolment, and in selecting patients according to prognostic factors to optimize the benefits of chemotherapy.
\end{abstract}

\section{Keywords}

Advanced Gastric Cancer, Chemotherapy, Targeted Therapy, Molecular Classification, Latin America

\footnotetext{
${ }^{*}$ Corresponding author.
}

How to cite this paper: Garrido, M., Jimenez-Fonseca, P., Solis, M.P., Carmona-Bayonas, A., Mondaca, S., Nervi, B. and Madrid, J. (2016) Role of Chemotherapy in Advanced Gastric Cancer: Review from a Latin American Perspective. Journal of Cancer Therapy, 7, 1-12. http://dx.doi.org/10.4236/jct.2016.71001 


\section{Introduction}

GC remains the fourth most common cancer and is second leading cause of cancer-related death worldwide, exceeded only by lung cancer [1]. The facts that over $70 \%$ of these cases occur in low-income countries and that the mortality rate in young cohorts in developed countries has risen [2] suggest that gastric cancer may be among the top ten causes of death by 2030 [3]. Latin American populations (LAP) include people who live in Central and South America, as well as immigrants from these countries in the United States (US), Europe (EU), and other countries. LA's total population is 606 million and rising; for example, the US includes 50.5 million people from LA, which represents $16.3 \%$ of the total population and is the fastest growing minority group in that country [4].

In LA, GC is a highly relevant disease given its prevalence, incidence, and associated mortality. In contrast to the US and EU, cancers related to infectious agents (liver cancer, stomach cancer, and cervix cancer) are exceedingly prevalent in LAP. GC remains common throughout many countries in Central and South America; for instance, in Chile, GC is the leading cause of cancer-related death in men and women combined [5] [6]. Figure 1 illustrates the different mortality and incidence rates from GC in the different countries in LA.

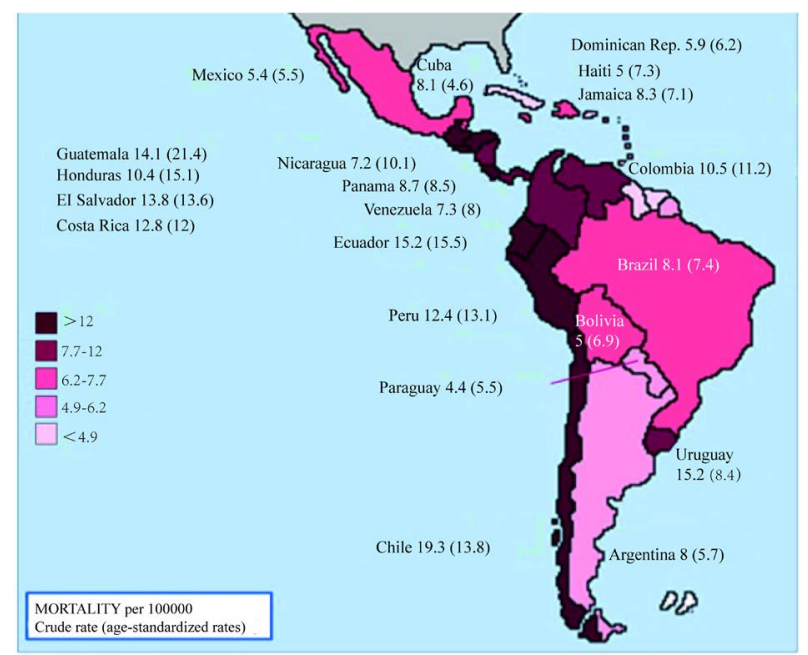

(a)

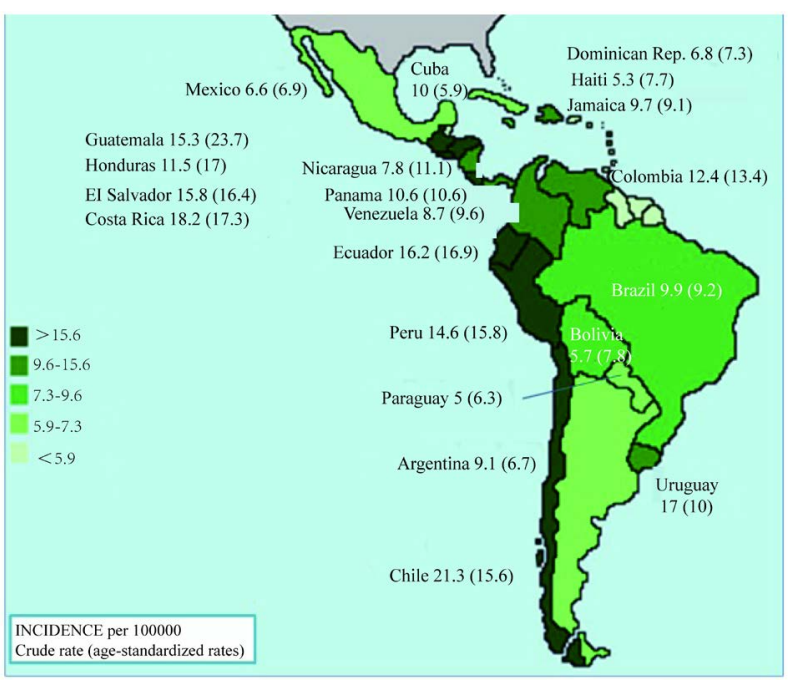

(b)

Figure 1. Map of mortality (a) and incidence (b) of GC in Latin America. The data are expressed as the crude rate (agestandardized rate) per 100000 inhabitants. 
The large proportion of GC patients who are diagnosed at stage IV and limited access to standard treatment may account for the high mortality associated with CG in LA. In the Dutch Eindhoven Cancer Registry, 50\% of patients were diagnosed with stage IV disease, and this proportion did not change between 1990 and 2007 [7]. However, these data are notavailable for many countries in LA, except in Brazil wherethe diagnosis of advanced GC is observed in $85 \%$ of cases [8]. However, these data are not available for many other countries in LA.

The present review analyzes standard chemotherapy and factors associated with it in metastastic GC with a special focus on trials and experiences in LA.

\section{Methods}

We performed a review of the literature published in English, Spanish, or Portuguese on chemotherapy and advanced GC. The search was performed in PubMed, The Cochrane Library, EMBASE, and LILACS without date limits. The search strategy included different combinations of the following terms: "metastatic or advanced GC", "stomach cancer", "stomach neoplasms", "esophagogastric junction cancer”, "Hispanic Americans", "Latin American”, "chemotherapy”, "targeted therapy”, “Clinical trials”, and "Phase III study”. In topics without consistent Phase III studies, Phase II trials or case series reports published in or presented at relevant meetings were likewise included. Articles were also identified by searching the major oncology congress databases, including those of the American Society of Clinical Oncology (ASCO), European Society of Medical Oncology (ESMO), International Gastric Cancer Association (IGCA), Chilean Society of Medical Oncology (SCOM), and Latin American Society of Gastrointestinal Oncology (SLAGO).

Bibliographic references from selected papers also served as sources of additional information.

\section{Chemotherapy Compared to Best Supportive Care}

In the 1990s, at least three randomized studies were published that had been designed to verify whether chemotherapy had any benefit in the treatment of advanced GC compared to best supportive care (BSC) [9]-[11]. In these trials, drug combinations containing 5-FU showed a $61 \%$ increase in survival with a hazard ratio (HR) of 0.39. The median survival time of the chemotherapy-treated groups was 9 - 11 months compared to 3 - 4 months in the groups without chemotherapy; this difference was significant. BSC compared to chemotherapy has not been studied in LA, despite the high relevance of GC. However, in a considerable proportion of patients, BSC is the primary treatment; for example, in the registry of the Colombian "Instituto de Cancerología" 27\% of patients with newly diagnosed GC were treated exclusively with BSC [12]. A meta-analysis published in 2010 examined thirty-five trials with a total of 5726 patients analysed for overall survival (OS) analysis. The comparison of chemotherapy versus BSC consistently demonstrated a significant benefit of chemotherapy in terms of OS (HR, 0.37; 95\% confidence interval (CI), 0.24 - 0.55) [13]. These results confirmed chemotherapy as the standard treatment for GC worldwide, and chemotherapy was adopted by SLAGO [14] and the SCOM guidelines.

\section{Combination Chemotherapy in GC (Table 1)}

\subsection{Classic Regimens}

Fluoropyrimidine and cisplatin were studied in randomized clinical trials in GC with the basic regimen of cisplatin $100 \mathrm{mg} / \mathrm{m}^{2}$ on day 1 and 5-FU $1000 \mathrm{mg} / \mathrm{m}^{2} /$ day by continuous infusion (Ci) on days $1-5$ every 4 weeks (FP4w); patients showed a response rate (RR) of 41\% (95\% CI: 28\% - 54\%) [15]. FAM (5-FU, adriamycin, and mitomycin) had a 15\% RR and OS of almost 9 months [16]. FAMTX (5-FU, adriamycin, and methotrexate) showed a RR of $8 \%-41 \%$ and median survival time of 5 - 10 months [17]. The epirubicin, cisplatin, and 5-FU regimen (ECF) was compared to FAMTX and exhibited improved RR ( $46 \%$ vs. $21 \%, \mathrm{P}=0.00003$ ), median OS (8.7 vs. 6.1 months, $\mathrm{P}=0.0005)$, and two-year survival rate $(14 \%$ vs. $5 \%, \mathrm{P}=0.03)$ [18].

FAMTX was compared to FP4w and ELF (etoposide, leucovorin, and 5-FU). Disease control (response rate plus stable disease) was 55\% for ELF, 46\% for FAMTX, and 63\% for FP4w. ELF showed a median OS of 7.2 months; FAMTX, 6.7 months, and FP4w, 7.2 months [19].

These results led FP4w and ECF to be considered the standard of care and were adopted in academic centers in LA; however, generally due to patient fragility, the proportion of patients with malnutrition and cost, FP4w was more extensively used. 
Table 1. Selected phase III trials of first-line chemotherapy and/or targeted therapies in advanced GC.

\begin{tabular}{|c|c|c|c|c|c|c|c|}
\hline Phase III Trial & Author & Year & $\mathrm{N}$ & $\begin{array}{l}\text { Treatment } \\
\text { Arms }\end{array}$ & ORR (\%) & $\begin{array}{c}\mathrm{mPFS} \\
(\mathrm{m})\end{array}$ & $\begin{array}{c}\mathrm{mOS} \\
(\mathrm{m})\end{array}$ \\
\hline Royal Mardsen (18) & Webb A & 1997 & 256 & $\begin{array}{l}\text { ECF } \\
\text { FAMTX }\end{array}$ & $\begin{array}{l}45 \\
21\end{array}$ & $\begin{array}{l}7.4 \\
3.4\end{array}$ & $\begin{array}{l}8.9 \\
5.7\end{array}$ \\
\hline EORTC (19) & Vanhoefer U & 2000 & 399 & $\begin{array}{c}\text { ELF } \\
\text { FP4w } \\
\text { FAMTX }\end{array}$ & $\begin{array}{c}9 \\
20 \\
12\end{array}$ & $\begin{array}{l}3.3 \\
4.1 \\
3.3\end{array}$ & $\begin{array}{l}7.2 \\
7.2 \\
6.7\end{array}$ \\
\hline V325 (20) & Ajani JA & 2007 & 445 & $\begin{array}{l}\text { DCF } \\
\text { FP4w }\end{array}$ & $\begin{array}{l}37 \\
25\end{array}$ & $\begin{array}{l}5.6 \\
3.7\end{array}$ & $\begin{array}{l}9.2 \\
8.6\end{array}$ \\
\hline Chinese trial (23) & Wang $\mathrm{J}$ & 2015 & 243 & $\begin{array}{l}\text { mDCF } \\
\text { FP3w }\end{array}$ & $\begin{array}{l}48.7 \\
33.9\end{array}$ & $\begin{array}{l}7.2 \\
4.9\end{array}$ & $\begin{array}{c}10.2 \\
8.5\end{array}$ \\
\hline ML 17032 (24) & Kang YK & 2009 & 316 & $\begin{array}{c}\text { XP } \\
\text { FP3W }\end{array}$ & $\begin{array}{l}46 \\
32\end{array}$ & $\begin{array}{l}5.6 \\
5.0\end{array}$ & $\begin{array}{c}10.5 \\
9.3\end{array}$ \\
\hline REAL-2 (25) & Cunningham E & 2008 & 1002 & $\begin{array}{l}\text { ECF } \\
\text { ECX } \\
\text { EOF } \\
\text { EOX }\end{array}$ & $\begin{array}{l}40.7 \\
46.4 \\
42.4 \\
47.9\end{array}$ & $\begin{array}{l}6.2 \\
6.7 \\
6.5 \\
7.0\end{array}$ & $\begin{array}{c}9.9 \\
9.9 \\
9.3 \\
11.2\end{array}$ \\
\hline AIO (26) & Al Batran SE & 2008 & 220 & $\begin{array}{l}\text { FLO } \\
\text { FLP }\end{array}$ & $\begin{array}{l}34.8 \\
24.5\end{array}$ & $\begin{array}{l}5.8 \\
3.9\end{array}$ & $\begin{array}{c}10.7 \\
8.8\end{array}$ \\
\hline French trial (31) & Dank M & 2008 & 333 & $\begin{array}{l}\text { IFL } \\
\text { FP4w }\end{array}$ & $\begin{array}{l}31.8 \\
25.8\end{array}$ & $\begin{array}{l}5.0 \\
4.2\end{array}$ & $\begin{array}{l}9.0 \\
8.7\end{array}$ \\
\hline $\begin{array}{l}\text { FFCD-Unicancer-GERCOR } \\
\qquad(32)\end{array}$ & Guimbaud R & 2014 & 416 & $\begin{array}{l}\text { FOLFIRI-ECX } \\
\text { ECX-FOLFIRI }\end{array}$ & $\begin{array}{l}39.2 \\
37.8\end{array}$ & $\begin{array}{l}5.3 \\
5.8\end{array}$ & $\begin{array}{l}9.5 \\
9.7\end{array}$ \\
\hline TOGA (40) & Bang YL & 2010 & 594 & $\begin{array}{l}\text { X(FU)P } \\
\text { X(FU)P-T }\end{array}$ & $\begin{array}{l}35 \\
47\end{array}$ & $\begin{array}{l}5.5 \\
6.7\end{array}$ & $\begin{array}{l}11.1 \\
13.8\end{array}$ \\
\hline TRIO-013/LOGiC (41) & Hech R & 2013 & 545 & $\begin{array}{c}\text { XOx } \\
\text { XOx-L }\end{array}$ & $\begin{array}{l}40 \\
53\end{array}$ & $\begin{array}{l}5.4 \\
6.0\end{array}$ & $\begin{array}{l}10.5 \\
12.2\end{array}$ \\
\hline AVAGAST (46) & Otshu A & 2011 & 774 & $\begin{array}{c}\text { X(FU)P } \\
\text { X(FU)P-Bev }\end{array}$ & $\begin{array}{c}37.4 \\
46\end{array}$ & $\begin{array}{l}5.3 \\
6.7\end{array}$ & $\begin{array}{l}10.1 \\
12.1\end{array}$ \\
\hline AVATAR (47) & Shen J & 2015 & 202 & $\begin{array}{c}\text { XP } \\
\text { XP-Bev }\end{array}$ & $\begin{array}{l}33.7 \\
40.7\end{array}$ & $\begin{array}{l}6.0 \\
6.3\end{array}$ & $\begin{array}{l}11.4 \\
10.5\end{array}$ \\
\hline EXPAND (43) & Lordick F & 2013 & 904 & $\begin{array}{c}\text { XP } \\
\text { XP-Cet }\end{array}$ & $\begin{array}{l}30 \\
30\end{array}$ & $\begin{array}{l}4.4 \\
5.6\end{array}$ & $\begin{array}{c}9.4 \\
10.7\end{array}$ \\
\hline REAL-3 (44) & Waddell T & 2013 & 553 & $\begin{array}{c}\text { EOX } \\
\text { EOX-Pan }\end{array}$ & $\begin{array}{l}42 \\
46\end{array}$ & $\begin{array}{l}7.4 \\
6.0\end{array}$ & $\begin{array}{c}11.3 \\
8.8\end{array}$ \\
\hline
\end{tabular}

mPFS: Median progression free survival; Bev: Bevacizumab; W: Weeks; ORR: Overall response rate; XOx: Capecitabine; Oxaliplatin; DCF: Docetaxel, cisplatin, 5-FU; N: Number of patients; ECF: Epirubicin, cisplatin, 5-FU; FLO: 5-FU, Leucovorin, oxaliplatin; mOS: Median overall survival; FAMTX: 5-FU, adriamycin, Methotrexate; m: Modified; L: Lapatinib; X(FU); P: Capecitabine or 5-FU and Cisplatin; FLP: 5-FU, leucovorin, cisplatin; Pan: Panitumumab; XP: Capecitabine, Cisplatin; IFL: Irinotecan, 5-FU, leucovorin; Cet: Cetuximab; T: Trastuzumab; Paclit-W: Paclitaxel weekly; NR: Not registered; EOX: Epirubicin, Oxaliplatin, Capecitabine; ELF: Epirubicine, leucovorin, 5-FU; ECX: Epirubicin, cisplatin, capecitabine; FOLFIRI: 5-FU, leucovorin, Irinotecan.

\subsection{Third-Generation Regimens}

DCF: The V325 clinical trial compared docetaxel $75 \mathrm{mg} / \mathrm{m}^{2}$ on day 1 , cisplatin $75 \mathrm{mg} / \mathrm{m}^{2}$ on day 1 and $5-\mathrm{FU}$ $750 \mathrm{mg} / \mathrm{m}^{2} / \mathrm{d}$ by Ci on days 1 - 5 every 3 weeks (DCF) with FP4w. DCF had a higher RR (36.7\% vs. 25.4\%), TTP (5.6 vs. 3.7 months), OS (9.2 vs. 8.6 months), clinical benefit and improved quality of life ( $<0.02)$ than FP4w [20] [21]. There was no difference in treatment-related deaths and the high percentage of febrile neutropenia and/or neutropenic infection declined from $29 \%$ to $12 \%$ with the administration of granulocyte colony-stimulating factor. However, due to its high toxicity (neutropenia grade $3 / 4,69 \%$ ), the modified DCF regimen (m DCF) was developed and was included in more studies [22], in addition to being considered standard of care for 
the Chinese population [23].

In LA, the DCF scheme is used in reference and academic centers and m DCF is the most commonly used regimen in younger patients with good performance status (PS).

XP: The ML 17032 phase III study showed similar OS for cisplatin $80 \mathrm{mg} / \mathrm{m}^{2}$ on day 1 and oral capecitabine $1000 \mathrm{mg} / \mathrm{m}^{2}$ twice daily on days 1 to 14 every 3 weeks (XP) in comparison to $5-\mathrm{FU} 800 \mathrm{mg} / \mathrm{m}^{2} / \mathrm{day}$ by Ci on days 1 - 5 and cisplatin $80 \mathrm{mg} / \mathrm{m}^{2}$ on day 1 every 3 weeks (FP3w) as first-line treatment. Median OS times were 10.5 and 9.3 months for XP and FP3w, respectively (unadjusted HR, 0.85; 95\% CI, $0.64-1.13$; P = 0.008) [24] (24). XP was combined with epirubicin (ECX) in a phase III clinical trial in advanced GC, and it was concluded that Capecitabine can replace 5-FU [25].

In LA, oral capecitabine is extensively used because it can replace the continuous infusion of 5-FU, which avoids the inconvenience and complications associated with central venous access and portable pumps; additionally, it shortens hospital stays.

Oxaliplatin regimens: The REAL-2 study tested the efficacy of oxaliplatin and capecitabine in a $2 \times 2$ noninferiority trial. A total of 600 randomized patients were treated with one of four different regimens: ECF, EOF (epirubicin, oxaliplatin and 5-FU), ECX, or EOX (epirubicin, oxaliplatin and capecitabine). The regimens containing capecitabine showed favorable OS compared to those containing 5-FU (10.9 vs. 9.6 months; HR, 0.86; $95 \%$ CI, 0.75 - 0.99). Regimens with oxaliplatin displayed favorable OS compared to those with cisplatin (10.4 vs. 10.1 months). However, this difference was not statistically significant (HR, 0.92; 95\% CI, 0.80 - 1.05). Serious side effects (approximately 40\%) appeared with both cisplatin (neutropenia and thromboembolism) and oxaliplatin (diarrhea and neuropathy) [25].

The AIO (Arbeitsgemeinschaft Internistische Onkologie) group compared 5-FU $2600 \mathrm{mg} / \mathrm{m}^{2}$ as a 24-hour infusion, leucovorin $200 \mathrm{mg} / \mathrm{m}^{2}$ and oxaliplatin $85 \mathrm{mg} / \mathrm{m}^{2}$ every 2 weeks (FLO regimen) to $5-\mathrm{FU} 2000 \mathrm{mg} / \mathrm{m}^{2}$ as a 24-hour infusion, leucovorin $200 \mathrm{mg} / \mathrm{m}^{2}$, and cisplatin $50 \mathrm{mg} / \mathrm{m}^{2}$ every 2 weeks (FLP combination). Increased progression-free survival (PFS) (FLO, 5.8 months vs. FLP, 3.9 months; $\mathrm{p}=0.077$ ) and OS (FLO, 10.7 vs. FLP, 8.8 months) was showed. However, FLO appeared to reduce hematological and cardiovascular toxicity in elderly people; therefore, oxaliplatin may be an alternative to cisplatin for the treatment of advanced GC in these patients [26]. The FOLFOX regimen (bolus 5-FU $400 \mathrm{mg} / \mathrm{m}^{2}, \mathrm{LV} 200 \mathrm{mg} / \mathrm{m}^{2}$, and 5-FU $600 \mathrm{mg} / \mathrm{m}^{2}$ by 24-hour Ci on days 1 and 2 and oxaliplatin $85 \mathrm{mg} / \mathrm{m}^{2}$ on day 1 every 2 weeks), a regimen that is widely used in LA, particularly in colorectal cancer, presented a good toxicity profile in a Chilean population with RR of $72.4 \%$ and median OS of 12.4 months [27]; the update of these results showed similar results, proving this scheme to be both active and safe [28] (28) (Table 2).

Table 2. Efficacy and selected toxicities of oxaliplatin and fluoropyrimidines in first-line chemotherapy in advanced GC.

\begin{tabular}{cc}
\hline Chemotherapy & 113 \\
\hline Number of Patients & $62(48-69)$ \\
Response Rate \% (95\% CI) & $7.1(6.1-8.2)$ \\
mPFS (95\% CI) & $9.6(7.8-11.3)$ \\
mOS (95\% CI) & 51.3 \\
OS at 1 year (\%) & 13 \\
Neutropenia Grade 3/4 (\%) & 3 \\
Febrile Neutropenia (\%) & 3 \\
Vomiting Grade 3/4 & 1 \\
Death (60 days) & 3 (3) \\
\hline
\end{tabular}


Oral capecitabine $1000 \mathrm{mg} / \mathrm{m}^{2}$ twice daily on days 1 - 14 and oxaliplatin $130 \mathrm{mg} / \mathrm{m}^{2}$ on day 1 every 3 weeks (XELOX) produced similar results to those with oxaliplatin and 5-FU, with a 42\% RR, 5.8 month TTP, and 11.1 months OS [29]. The toxicity profile differed (more diarrhea and neuropathy; less thrombosis and neutropenia), but was not inferior to that of cisplatin regimens. In elderly patients, XELOX displayed similar results [30].

In LA, the FOLFOX regimen is broadly used instead of FP4w regimens, especially in elderly patients or those who are not candidates for cisplatin-containing regimens.

FOLFIRI/IFL: IFL was compared to FP4w in a French phase III trial. For IFL versus FP4w, RR values were $31.8 \%$ and $25.8 \%$; TTP was 5.0 months and 4.2 months $(\mathrm{p}=0.088)$, and OS rates were 9.0 and 8.7 months, respectively [31]. The IFL group exhibited a superior safety profile, making this regimen a suitable alternative for fragile patients or co-morbidities that limit the use of cisplatin.

The FOLFIRI regimen (irinotecan $180 \mathrm{mg} / \mathrm{m} 2, \mathrm{LV} 400 \mathrm{mg} / \mathrm{m}^{2}$, and bolus 5-FU $400 \mathrm{mg} / \mathrm{m}^{2}$ on day 1 and 5-FU $2400 \mathrm{mg} / \mathrm{m}^{2}$ for 46 hrs every 2 weeks) was evaluated in two sequences with ECX (FOLFIRI-ECX versus ECX-FOLFIRI). There were no differences in PFS or OS [32]. The potential benefit and improved tolerability of irinotecan-based regimens make IFL or FOLFIRI good choices for prolonging the chemotherapy treatment period and for combinations with new targeted agents in GC. In LA, the FOLFIRI regimen has been used as second-line treatment for patients with a PS $<2$.

\subsection{New Molecular Targeted Drugs in Advanced Gastric Cancer}

GC over-expresses a large number of proteins and exhibits the amplification of genes involved in transduction and cellular growth. The molecular classification of GC in 3 or 4 subgroups provides for an understanding of the clinical differences and variable responses to chemotherapy in patients with a similar disease based on classic parameters [33] [34]. This molecular classification elucidates new therapeutic options based on molecular subtype or new molecular targets. The findings of The Cancer Genome Atlas Research Network included Epstein-Barr virus-associated GC; this group accounts for $23 \%$ of GC cases in LA [35] and these patients probably have a better prognosis [36].

Molecular targets are being tested in different populations in LA; for example, HER2 positivity in intestinal GC was $12 \%$ in Peru [37] and 16.4\% in Chile [38]. These percentages are lower than the previously reported 24\% in the validation study by Hoffman et al. [39], which raises the biological differences in different regions.

Phase III clinical trials using targeted agents are being developed; some of the published studies are described below.

Anti-HER/ErbB2: The TOGA trial used capecitabine $1000 \mathrm{mg} / \mathrm{m}^{2}$ administered orally twice per day for 14 days, followed by a 1-week rest, or fluorouracil $800 \mathrm{mg} / \mathrm{m}^{2}$ per day by continuous intravenous infusion on days 1 - 5 of each cycle, cisplatin $80 \mathrm{mg} / \mathrm{m}^{2}$ on day 1 by intravenous infusion, and trastuzumab by intravenous infusion at $8 \mathrm{mg} / \mathrm{kg}$ on day 1 of the first cycle followed by $6 \mathrm{mg} / \mathrm{kg}$ every 3 weeks until disease progression [40]. A total of $22.1 \%$ (584) of the patients were HER2+ and were randomized to receive treatment with (294 patients) or without (290 patients) trastuzumab. The results of the study established a clear benefit of chemotherapy with trastuzumab in terms of OS (13.5 vs. 11.1 months; $\mathrm{p}=0.0048)$. Fifty-two of these patients were from LA and showed a clear benefit of trastuzumab (HR, 0.44; 95\% CI, 0.21 - 0.90). The TRIO-013/LOGIC trial exhibited a benefit in terms of PFS but not OS in HER2-positive patients treated with lapatinib and XELOX as first-line therapy [41]. The promising results obtained with trastuzumab led to the development of other phase II and III trials with trastuzumab or new anti-HER-2-targeted agents, such as lapatinib, pertuzumab, trastuzumab, emtansine (TDM-1), afatinib or dacomitinib, in combination with different chemotherapies (ECX, ECF, XP, XELOX, or FOLFOX). These trials are currently active, recruiting or in the process of being reported [42].

Anti-EGFR1: Two phase III studies, the EXPAND trial [43] (cisplatin and capecitabine with or without cetuximab) and the REAL-3 trial [44] (EOX with or without panitumumab), exhibited no benefit in PFS or OS. A small number of patients from LA were included in the EXPAND trial.

Anti-VEGF: The AVAGAST study (XP with and without bevacizumab) did not accomplish its primary endpoint of extending OS in patients treated with bevacizumab [45]; however, subgroup analyses demonstrated significantly longer OS in patients from non-Asian regions. Furthermore, a biomarker study showed that plasma VEGF-A and tumor neuropilin-1 are strong candidate biomarkers for predicting clinical outcome in patients with AGC who are treated with bevacizumab [46]. A subgroup of Pan-American patients (19\%) benefited from the addition of bevacizumab, with a median OS rate of 11.5 versus 6.8 months (HR, 0.63; 95\% CI, 0.43 - 0.94). 
The AVATAR trial in a Chinese population yielded similar results to AVAGAST [47].

Ramucirumab is a fully humanized IgG1 monoclonal antibody targeting VEGF receptor-2. Its clinical activity as a second-line therapy for advanced GC was verified in the REGARD study. In this trial, 335 patients were randomized to BSC versus ramucirumab. The HR for OS was 0.776 (95\% CI, $0.603-0.998 ; \mathrm{p}=0.0473)$. Median OS was 5.2 months for ramucirumab and 3.8 months for placebo [48]. The RAINBOW study of ramucirumab combined with paclitaxel in second-line therapy documented a significant increase in OS, establishing it as the new standard in this setting [49]. Forty-one patients in the REGARD and 23 in the RAINBOW trials were from LA.

Anti-PI3K-AKT-mTOR: This pathway has often been found to be activated in gastric cancer. A specific inhibitor of this pathway, everolimus, was evaluated in a phase III trial (GRANITE-1) in patients with two or more lines of treatment versus BSC. Median OS was 5.39 months with everolimus versus 4.34 months with BSC (HR, 0.90; 95\% CI, 0.75 - 1.08; P = 0.1244); thirty-five Hispanic or Latino patients were included in this trial [50]. More studies are required with new inhibitors as first-line therapies, especially in patients with mTOR activation. The particular relevance of this pathway has been demonstrated in the new molecular classification of GC.

Anti-HGF-c-MET: This pathway has become an increasingly interesting target in many types of cancer. In gastric cancer, c-MET amplification is observed in $2 \%$ of patients. High MET expression, as determined by immunohistochemistry, may predict a clinical benefit from rilotumumab plus ECX in gastric cancer patients and may be associated with poor prognosis in ECX-treated patients [51]. A phase III clinical trial with rilotumumab is ongoing and includes centers in Mexico and Brazil.

\section{Prognostic Factors in Patients with Advanced GC Treated with Chemotherapy}

Prognostic models help to determine which patients will have a poor prognosis with standard treatment and in what circumstances alternative treatment strategies should be developed. Prognostic models for advanced cancer can also be used to stratify patients into subgroups in clinical trials to compare uniform groups of patients and contribute to the decision-making process involving physicians and patients.

In advanced GC, several studies have evaluated prognostic factors associated with worse survival.

European Population: The Royal Marsden Hospital's prognostic index has been validated in a larger sample. It was evaluated in a cohort of 1080 patients with advanced GC who were recruited in 3 clinical trials using chemotherapy. Mean OS of this cohort was 7.9 months. In the multivariate analysis, 4 prognostic factors were significantly associated with worse prognosis: performance status (PS) based on the Eastern Cooperative Oncology Group (ECOG) score $\geq 2$ (HR, 1.58), the presence of peritoneal metastases (HR, 1.33), alkaline phosphatase $\geq 100 \mathrm{U} / \mathrm{I}(\mathrm{HR}, 1.41)$, and the presence of liver metastases (HR, 1.41) [52].

Patients without any of these characteristics were classified as low risk, those with 1 or 2 variables were categorized as intermediate risk, and the high risk group comprised patients with 3 or 4 characteristics. Median survival times for the three groups were 11.8, 7.4, and 4.1 months, respectively. This prognostic index was validated with data from the REAL-2 trial, confirming its discriminatory capacity [53].

A Netherlands-based study evaluated 350 patients with advanced esophageal tumors who were treated with palliative cisplatin-based chemotherapy in 6 different phase I and phase II studies. The factors associated with worse prognosis in this series were ECOG PS $\geq 2$, elevated LDH, the presence of unresectable loco-regional disease, and the presence of disseminated metastatic disease [54].

Korean Population: Kim et al. evaluated 304 patients with advanced GC who were treated at a single center with cisplatin-based chemotherapy. In the multivariate analysis, the authors detected 5 factors associated with poor prognosis: poor performance status (HR, 1.46), elevated bilirubin (HR, 2.04), peritoneal metastases (HR, 1.73), bone metastases (HR, 3.11), and more than one metastatic site (HR, 1.22). This model enabled patients to be stratified into three prognostic groups with 1 -year survival rates of $34.6 \%, 20.7 \%$, and $1.7 \%$, respectively $(\mathrm{p}<$ 0.0001) [55].

At Samsung Medical Center, a retrospective analysis was conducted of 1455 gastric cancer patients receiving first-line chemotherapy. In the multivariate analysis, they found 6 predictors that were associated with worse prognosis based on relative risk (RR): no prior gastrectomy (RR, 1.1), albumin $<3.6 \mathrm{~g} / \mathrm{dl}$ (RR, 1.2), alkaline phosphatase $>85 \mathrm{U} / 1$ (RR, 1.2), ECOG PS $\geq 2$ (RR, 1.6), bone metastases (RR, 1.4), and ascitis (RR, 1.4). This model classified patients into 3 prognostic categories, with median OS times of 12.5, 7, and 2.8 months [56].

Only the Royal Marsden Hospital prognostic index has been validated in the setting of a clinical trial, such as 
the REAL-2 study, but none of the prognostic indices have been validated independently in real clinical practice. The Royal Marsden Hospital prognostic factor has been evaluated in European and Asian populations without targeted therapy associated with chemotherapy.

LA population: Specific studies of prognostic factors in patients with advanced GC treated with chemotherapy have not been performed; however, the AGAMENON study organized by a Spanish and Chilean collaborative group is assessing prognostic factors in the real clinical practice of patients with advanced GC treated with chemotherapy and/or targeted therapy in a multicenter study. The data that prompted this study were presented at ESMO. Spanish and Chilean populations were included and eight independent prognostic factors were identified in the multivariate analysis (Table 3): two or more chronic co-morbidities (HR, 1.19; 95\% CI, 1.04 - 1.36), ECOG performance status $\geq 2$ (HR, 1.40; 95\% CI, 0.99 - 2.14), the presence of signet ring cells (HR, 1.37; 95\% CI, 1.07 - 1.72), HER2-overexpressing tumors treated with trastuzumab (HR, 0.71; 95\% CI, 0.50 - 0.96), two or more sites of metastatic disease (HR 1.26; 95\% CI, 1.08 - 1.63), carcinoembryonic antigen (CEA) $\geq 20 \mathrm{ng} / \mathrm{ml}$ (HR, 1.32; 95\% CI, 1.23 - 1.69), the presence of bone metastasis (HR, 1.99; 95\% CI, 1.37 - 2.87) and ascitis (HR, 1.67; 95\% CI, 1.26 - 2.21). These variables were integrated into a prognostic index that classified patients into low $(\mathrm{n}=84)$ (Group 1), moderate $(\mathrm{n}=324)($ Group 2), and high $(\mathrm{n}=42)($ Group 3) risk categories, with median OS times of 13.9 months in Group 1, 8.9 months in Group 2, and 6.2 months in Group 3; these differences in OS were statistically significant $(\mathrm{p}<0.001)$ [57], a validation study is ongoing (Table 4).

\section{Conclusions}

People in LA have a very real health problem related to advanced CG. It is estimated that in the upcoming years, GC may gain in relevance due to increased risk factors, such as increased longevity, increased obesity, the lack of programs to identify GC in high-risk populations, the high rate of infection and re-infection with Helicobacter pylori, and limited access to health systems.

Table 3. Risk factors for overall survival (OS) identified in a multivariate analysis.

\begin{tabular}{ccc} 
Risk Factor (RF) & HR & 95\% CI \\
Comorbidities, $\geq 2$ & 1.19 & $1.04-1.36$ \\
ECOG, $\geq 2$ & 1.40 & $0.99-2.14$ \\
Signet Ring Cells, $>50 \%$ & 1.37 & $1.07-1.72$ \\
Her2 Treated with Trastuzumab & 0.71 & $0.50-0.96$ \\
Metastatic Sites, $\geq 2$ & 1.26 & $1.08-1.63$ \\
CEA, $\geq 20$ & 1.32 & $1.23-1.69$ \\
Bone Metastases & 1.99 & $1.37-2.89$ \\
Ascitis & 1.67 & $1.26-2.21$ \\
\hline
\end{tabular}

Table 4. Three groups of risk with differences in median OS (mOS) based on the eight risk factors.

\begin{tabular}{ccc}
\hline Prognostic Index & mOS & p \\
Group 1: Low (0 RF) & 13.4 & $<0.001$ \\
Group 2: Moderate (1 - 2 RF) & 6.2 \\
Group 3: High ( $>2 \mathrm{RF})$ & \\
\hline
\end{tabular}


Despite considerable advances in the chemotherapeutic treatment of GC, mortality of advanced GC in LA remains high. People from LA are under-represented in multicenter clinical trials and specific studies in this population are rare, with the exception of isolated reports of experience in research centers. Finally, not a single report of targeted therapies in this population exists.

The identification of specific molecular subtypes and risk factors that are more prevalent in people from LA using TCGA has revealed specific characteristics of this population that require further analysis and specific studies to assess the true impact of treatments and chemotherapy regimens.

Everyday, patients who do not meet the conditions for clinical trials, as well as those with chronic and acute co-morbidities, advanced age, and poor PS are not included in clinical trials, and therefore, the effect they may have on the final prognosis of advanced GC has not been evaluated. It is possible that these patients respond differently than clinical trial subjects. In this sense, the AGAMENON study is moving in the right direction by evaluating prognostic factors in real clinical practice with a clear role for persons from LA. We hope that this is merely the first of many studies on the impact of treatment on populations where advanced GC is the top priority, as it is in LA.

\section{References}

[1] Ferlay, J., Shin, H.R., Bray, F., Forman, D., Mathers, C. and Parkin, D.M. (2010) Estimates of Worldwide Burden of Cancer in 2008: GLOBOCAN. International Journal of Cancer, 127, 2893-2917. http://dx.doi.org/10.1002/ijc.25516

[2] Anderson, W.F., Camargo, M.C., Fraumeni Jr., J.F., Correa, P., Rosenberg, P.S. and Rabkin, C.S. (2010) Age-Specific Trends in Incidence of Noncardia Gastric Cancer in US Adults. JAMA, 303, 1723-1728. http://dx.doi.org/10.1001/jama.2010.496

[3] Mathers, C.D. and Loncar, D. (2006) Projections of Global Mortality and Burden of Disease from 2002 to 2030. PLoS Medicine, 3, e442. http://dx.doi.org/10.1371/journal.pmed.0030442

[4] Ennis, S.R., Rios-Vargas, M. and Albert, N.G. (2011) The Hispanic Population: 2010: 2010 Census Briefs. United States Census Bureau, Washington DC.

[5] Bertuccio, P., Chatenoud, L., Levi, F., Praud, D., Ferlay, J., Negri, E., Malvezzi, M. and La Vecchia, C. (2009) Recent Patterns in Gastric Cancer: A Global Overview. International Journal of Cancer, 125, 666-673. http://dx.doi.org/10.1002/ijc.24290

[6] Departamento de Estadísticas e Información de Salud (2014) Series y gráficos de mortalidad. www.deis.cl/?p=2543

[7] Dassen, A.E., Lemmensm, V.E., van de Poll-Franse, L.V., Creemers, G.J., Brenninkmeijer, S.J., Lips, D.J., Wurff, V.D., Bosscha, K. and Coebergh J.W. (2010) Trends in Incidence, Treatment and Survival of Gastric Adenocarcinoma between 1990 and 2007: A Population-Based Study in the Netherlands. European Journal of Cancer, 46, 1101-1110. http://dx.doi.org/10.1016/j.ejca.2010.02.013

[8] Zilberstein, B., Malheiros, C., Lourenco, L., Kassab, P., Jacob, C.E., Weston, A.C., Bresciani, C.J., Castro, O., Gama-Rodriguez, J., do Consenso, G., et al. (2013) Brazilian Consensus in Gastric Cancer: Guidelines for Gastric Cancer in Brazil. Arquivos Brasileiros de Cirurgia Digestiva, 26, 2-6. http://dx.doi.org/10.1590/S0102-67202013000100002

[9] Pyrhönen, S., Kuitunen, T., Nyandoto, P. and Kouri, M. (1995) Randomised Comparison of Fluorouracil, Epidoxorubicin and Methotrexate (FEMTX) plus Supportive Care with Supportive Care Alone in Patients with Non-Resectable Gastric Cancer. British Journal of Cancer, 71, 587-591. http://dx.doi.org/10.1038/bjc.1995.114

[10] Murad, A.M., Santiago, F.F., Petroianu, A., Rocha, P.R., Rodrigues, M.A. and Rausch, M. (1993) Modified Therapy with 5-Fluorouracil, Doxorubicin, and Methotrexate in Advanced Gastric Cancer. Cancer, 72, 37-41. http://dx.doi.org/10.1002/1097-0142(19930701)72:1<37::AID-CNCR2820720109>3.0.CO;2-P

[11] Glimelius, B., Ekström, K., Hoffman, K., Graf, W., Sjödén, P.O., Haglund, U., Svensson, C., Enander, L.K., Linné, T., Sellstrom, H. and Heuman, R. (1997) Randomized Comparison between Chemotherapy plus Best Supportive Care with Best Supportive Care in Advanced Gastric Cancer. Annals of Oncology, 8, 163-168. http://dx.doi.org/10.1023/A:1008243606668

[12] Pardo, C., Murillo, R., Piñeros, M. and Castro, M.Á. (2003). Casos Nuevos de cáncer en el Instituto Nacional de Cancerología, Colombia, 2002. Revista Colombiana de Cancerología, 7, 4-19.

[13] Wagner, A.D., Unverzagt, S., Grothe, W., Kleber, G., Grothey, A., Haerting, J. and Fleig, W.E. (2010) Chemotherapy for Advanced Gastric Cancer. Cochrane Database of Systematic Reviews, 17, CD004064. http://dx.doi.org/10.1002/14651858.cd004064.pub3

[14] Müller, B., Gallardo, J., González, P., Cazap, E., Carraro, S., Baeza, R., Garbino, C. and Villar, H. (2009) Conclusiones del Primer Consenso Latinoamericano en Cáncer Gástrico: Terapias perioperatorias y tratamiento paliativo. Revista Chilena de Cancerología y Hematología, 1, 1-4. 
[15] Lacave, A.J., Barón, F.J., Antón, L.M., Estrada, E., De Sande, L.M., Palacio, I., Esteban, E., Gracia, J.M., Bueza, J.M., Fernandez, O.A., et al. (1991) Combination Chemotherapy with Cisplatin and 5-Fluorouracil 5-Day Infusion in the Therapy of Advanced Gastric Cancer: A Phase II Trial. Annals of Oncology, 2, 751-754.

[16] MacDonald, J.S., Schein, P.S., Woolley, P.V., Smythe, T., Ueno, W., Hoth, D., Smith, F., Boiron, M., Gisselbretch, C., Brunet, R. and Lagarde, C. (1980) 5-Fluorouracil, Doxorubicin, and Mitomycin (FAM) Combination Chemotherapy for Advanced Gastric Cancer. Annals of Internal Medicine, 93, 533-536. http://dx.doi.org/10.7326/0003-4819-93-4-533

[17] Wils, J.A., Klein, H.O., Wagener, D.J., Bleiberg, H., Reis, H., Korsten, F., Conroy, T., Fickers, M., Leyvraz, S. and Buyse, M. (1991) Sequential High-Dose Methotrexate and Fluorouracil Combined with Doxorubicin-A Step Ahead in the Treatment of Advanced Gastric Cancer: A Trial of the European Organization for Research and Treatment of Cancer Gastrointestinal Tract Cooperative Group. Journal of Clinical Oncology, 9, 827-831.

[18] Webb, A., Cunningham, D., Scarffe, J.H., Harper, P., Norman, A., Joffe, J.K., Hughes, M., Mansi, J., Findlay, M., Hill, A., et al. (1997) Randomized Trial Comparing Epirubicin, Cisplatin, and Fluorouracil versus Fluorouracil, Doxorubicin, and Methotrexate in Advanced Esophagogastric Cancer. Journal of Clinical Oncology, 15, 261-267. http://dx.doi.org/10.1016/S0959-8049(97)86090-X

[19] Vanhoefer, U., Rougier, P., Wilke, H., Ducreux, M.P., Lacave, A.J., Van Cutsem, E., Planker, M., Santos, J.G., Piedbois, P., Paillot, B., et al. (2000) Final Results of a Randomized Phase III Trial of Sequential High-Dose Methotrexate, Fluorouracil, and Doxorubicin versus Etoposide, Leucovorin, and Fluorouracil versus Infusional Fluorouracil and Cisplatin in Advanced Gastric Cancer: A Trial of the European Organization for Research and Treatment of Cancer Gastrointestinal Tract Cancer Cooperative Group. Journal of Clinical Oncology, 8, 2648-2657.

[20] Ajani, J.A., Moiseyenko, V.M., Tjulandin, S., Majlis, A., Constenla, M., Boni, C., Rodrigues, A., Fodor, M., Chao, Y. and Voznyi, E. (2007) Clinical Benefit with Docetaxel plus Fluorouracil and Cisplatin Compared with Cisplatin and Fluorouracil in a Phase III Trial of Advanced Gastric or Gastroesophageal Cancer Adenocarcinoma: The V-325 Study Group. Journal of Clinical Oncology, 25, 3205-3209. http://dx.doi.org/10.1200/JCO.2006.10.4968

[21] Ajani, J.A., Moiseyenko, V.M., Tjulandin, S., Majlis, A., Constenla, M., Boni, C., Rodrigues, A., Fodor, M., Chao, Y. and Voznyi, E. (2007) Quality of Life with Docetaxel plus Cisplatin and Fluorouracil Compared with Cisplatin and Fluorouracil from a Phase III Trial for Advanced Gastric or Gastroesophageal Adenocarcinoma: The V-325 Study Group. Journal of Clinical Oncology, 25, 3210-3216. http://dx.doi.org/10.1200/JCO.2006.08.3956

[22] Inal, A., Kaplan, M.A., Kucukoner, M. and Isikdogan, A. (2012) Docetaxel and Cisplatin plus Fluorouracil Compared with Modified Docetaxel, Cisplatin, and 5-Fluorouracil as First-Line Therapy for Advanced Gastric Cancer: A Retrospective Analysis of Single Institution. Neoplasma, 59, 233-236. http://dx.doi.org/10.4149/neo_2012_030

[23] Wang, J., Xu, R., Li, J., Bai, Y., Liu, T., Jiao, S., Dai, G., Xu, J., Liu, Y., Fan, N., et al. (2016) Randomized Multicenter Phase III Study of a Modified Docetaxel and Cisplatin plus Fluorouracil Regimen Compared with Cisplatin and Fluorouracil as First-Line Therapy for Advanced or Locally Recurrent Gastric Cancer. Gastric Cancer, 19, $234-244$.

[24] Kang, Y.K., Kang, W.K., Shin, D.B., Chen, J., Xiong, J., Wang, J., Lichinitser, M., Guan, Z., Khasanov, R., Zheng, L., et al. (2009) Capecitabine/Cisplatin versus 5-Fluorouracil/Cisplatin as First-Line Therapy in Patients with Advanced Gastric Cancer: A Randomised Phase III Noninferiority Trial. Annals of Oncology, 20, 666-673. http://dx.doi.org/10.1093/annonc/mdn717

[25] Cunningham, D., Starling, N., Rao, S., Iveson, T., Nicolson, M., Coxon, F., Middleton, G., Daniel, F., Oates, J. and Norman, A.R. (2008) Capecitabine and Oxaliplatin for Advanced Esophagogastric Cancer. The New England Journal of Medicine, 358, 36-46. http://dx.doi.org/10.1056/NEJMoa073149

[26] Al-Batran, S.E., Hartmann, J.T., Probst, S., Schmalenberg, H., Hollerbach, S., Hofheinz, R., Rethwisch, V., Seipelt, G., Homann, N. and Wilhelm, G. (2008) Phase III Trial in Metastatic Gastroesophageal Adenocarcinoma with Fluorouracil, Leucovorin plus either Oxaliplatin or Cisplatin: A Study of the Arbeitsgemeinschaft Internistische Onkologie. Journal of Clinical Oncology, 26, 1435-1442. http://dx.doi.org/10.1200/JCO.2007.13.9378

[27] Garrido, M., Melgoza, G., Galindo, H., Madrid, J., Sánchez, C., Nervi, B., Alvarez, M. and Orellana, E. (2007) Treatment of Advanced Gastric Cancer with Oxaliplatin plus 5-Fluorouracil/Leucovorin (FOLFOX-4 Chemotherapy). Revista Médica de Chile, 135, 1380-1387.

[28] Garrido, M., Vicente Conesa, M.A., Carmona-Bayonas, A., Faez, L., Custodio, A., López, C., Visa, L., Gallego Plazas, J., Fernandez Arrojo, S., Ramchandani, A., et al. (2014) First-Line Chemotherapy for Patients with Gastroesophageal Adenocarcinoma in the Community Setting: A Multicenter Cohort of 418 Patients. Annals of Oncology, 25, iv232.

[29] Luo, H.Y., Xu, R.H., Wang, F., Qiu, M.Z., Li, Y.H., Li, F.H., Zhou, Z.W. and Chen, X.Q. (2010) Phase II Trial of XELOX as First-Line Treatment for Patients with Advanced Gastric Cancer. Chemotherapy, 56, 94-100. http://dx.doi.org/10.1159/000305256

[30] Xiang, X.J., Zhang, L., Qiu, F., Yu, F., Zhan, Z.Y., Feng, M., Yan, J., Zhao, J.G. and Xiong, J.P. (2012) A Phase II Study of Capecitabine plus Oxaliplatin as First-Line Chemotherapy in Elderly Patients with Advanced Gastric Cancer. 
Chemotherapy, 58, 1-7. http://dx.doi.org/10.1159/000335585

[31] Dank, M., Zaluski, J., Barone, C., Valvere, V., Yalcin, S., Peschel, C., Wenczl, M., Goker, E., Cisar, L., Wang, K. and Bugat, R. (2008) Randomized Phase III Study Comparing Irinotecan Combined with 5-Fluorouracil and Folinic Acid to Cisplatin Combined with 5-Fluorouracil in Chemotherapy Naive Patients with Advanced Adenocarcinoma of the Stomach or Esophagogastric Junction. Annals of Oncology, 19, 1450-1457. http://dx.doi.org/10.1093/annonc/mdn166

[32] Guimbaud, R., Louvet, C., Ries, P., Ychou, M., Maillard, E., André, T., Gornet, J.M., Aparicio, T., Nguyen, S., Azzedine, A., et al. (2014) Prospective, Randomized, Multicenter, Phase III Study of Fluorouracil, Leucovorin, and Irinotecan versus Epirubicin, Cisplatin, and Capecitabine in Advanced Gastric Adenocarcinoma: A French Intergroup (Fédération Francophone de Cancérologie Digestive, Fédération Nationale des Centres de Lutte Contre le Cancer, and Groupe Coopérateur Multidisciplinaire en Oncologie) Study. Journal of Clinical Oncology, 32, 3520-3526. http://dx.doi.org/10.1200/JCO.2013.54.1011

[33] Cancer Genome Atlas Research Network (2014) Comprehensive Molecular Characterization of Gastric Adenocarcinoma. Nature, 513, 202-209.

[34] Lei, Z., Tan, I.B., Das, K., Deng, N., Zouridis, H., Pattison, S., Chua, C., Feng, Z., Guan, I.K., Ooi, C.H., et al. (2013) Identification of Molecular Subtypes of Gastric Cancer with Different Responses to PI3-Kinase Inhibitors and 5-Fluorouracil. Gastroenterology, 145, 554-565. http://dx.doi.org/10.1053/j.gastro.2013.05.010

[35] Corvalán, A., Akiba, S., Valenzuela, M.T., Cumsille, M.A., Koriyama, C., Argandoña, J., Backhouse, C., Bal, M., Mena, F., Palma, M. and Eizuru, Y. (2005) Clinical and Molecular Features of Cardial Gastric Cancer Associated to Epstein Barr Virus. Revista Médica de Chile, 133, 753-760. http://dx.doi.org/10.4067/S0034-98872005000700001

[36] Camargo, M.C., Kim, W.H., Chiaravalli, A.M., Kim, K.M., Corvalan, A.H., Matsuo, K., Yu, J., Sung, J.J., Herrera-Goepfert, R., Meneses-Gonzalez, F., et al. (2014) Improved Survival of Gastric Cancer with Tumour Epstein-Barr Virus Positivity: An International Pooled Analysis. Gut, 63, 236-243.

[37] Beltran, B. and Yabar, A. (2010) Expresión de HER2 en Cancer Gástrico en el Perú. Revista de Gastroenterología del Perú, 30, 324-327

[38] Roa, I., Slater, J., Carvajal, D., Schalper, K., de Toro, G., Ares, R., Game, A., León, J. and de Aretxabala, X. (2013) HER2 Gene Amplification and Overexpression in Advanced Gastric Cancer. Revista Médica de Chile, 141, 1411-1419. http://dx.doi.org/10.4067/S0034-98872013001100007

[39] Hofmann, M., Stoss, O., Shi, D., Büttner, R., van de Vijver, M., Kim, W., Ochial, A., Ruschoff, J. and Henkel, T. (2008) Assessment of a HER2 Scoring System for Gastric Cancer: Results from a Validation Study. Histopathology, 52, 797-805. http://dx.doi.org/10.1111/j.1365-2559.2008.03028.x

[40] Bang, Y.J., Van Cutsem, E., Feyereislova, A., Chung, H.C., Shen, L., Sawaki, A., Lordick, F., Ohtsu, A., Omuro, Y., Satoh, T., et al. (2010) Trastuzumab in Combination with Chemotherapy versus Chemotherapy Alone for Treatment of HER2-Positive Advanced Gastric or Gastro-Oesophageal Junction Cancer (ToGA): A Phase 3, Open-Label, Randomised Controlled Trial. The Lancet, 376, 687-697. http://dx.doi.org/10.1016/S0140-6736(10)61121-X

[41] Hecht, J.R., Bang, Y.J., Qin, S., Chung, H.C., Xu, J.M., Park, J., Jeziorski, Y., Hoff, P., Sobrero, A., Salman, P., et al. (2013) Lapatinib in Combination with Capecitabine plus Oxaliplatin (CapeOx) in HER2-Positive Advanced or Metastatic Gastric, Esophageal, or Gastroesophageal Adenocarcinoma (AC): The TRIO-013/LOGiC Trial. Journal of Clinical Oncology, 31, LBA4001.

[42] Garrido, M., Fonseca, P.J., Vieitez, J.M., Frunza, M. and Lacave, A.J. (2014) Challenges in First Line Chemotherapy and Targeted Therapy in Advanced Gastric Cancer. Expert Review of Anticancer Therapy, 14, 887-900. http://dx.doi.org/10.1586/14737140.2014.915194

[43] Lordick, F., Kang, Y.K., Chung, H.C., Salman, P., Oh, S.C., Bodoky, G., Kurteva, G., Volovat, C., Moiseyenki, V.M., Gorbunova, V., et al. (2013) Capecitabine and Cisplatin with or without Cetuximab for Patients with Previously Untreated Advanced Gastric Cancer (EXPAND): A Randomised, Open-Label Phase 3 Trial. The Lancet Oncology, 14, 490-499. http://dx.doi.org/10.1016/S1470-2045(13)70102-5

[44] Waddell, T., Chau, I., Cunningham, D., Gonzalez, D., Frances, A., Okines, C., Wotherspoon, A., Saffery, C., Middleton, G., Wadsley, J., et al. (2013) Epirubicin, Oxaliplatin, and Capecitabine with or without Panitumumab for Patients with Previously Untreated Advanced Oesophagogastric Cancer (REAL3): A Randomised, Open-Label Phase 3 Trial. The Lancet Oncology, 14, 481-489. http://dx.doi.org/10.1016/S1470-2045(13)70096-2

[45] Ohtsu, A., Shah, M.A., Van Cutsem, E., Rha, S.Y., Sawaki, A., Park, S.R., Lim, H.Y., Yamada, Y., Wu, J., Langer, B., et al. (2011) Bevacizumab in Combination with Chemotherapy as First-Line Therapy in Advanced Gastric Cancer: A Randomized, Double-Blind, Placebo-Controlled Phase III Study. Journal of Clinical Oncology, 29, 3968-3976. http://dx.doi.org/10.1200/JCO.2011.36.2236

[46] Van Cutsem, E., de Haas, S., Kang, Y.K., Ohtsu, A., Tebbutt, N.C., Xu, J.M., Yong, W.P., Langer, B., Delmar, P., Scherer, S.J. and Shah, M.A. (2012) Bevacizumab in Combination with Chemotherapy as First-Line Therapy in Advanced Gastric Cancer: A Biomarker Evaluation from the AVAGAST Randomized Phase III Trial. Journal of Clinical 
Oncology, 30, 2119-2127. http://dx.doi.org/10.1200/JCO.2011.39.9824

[47] Shen, L., Li, J., Xu, J., Pan, H., Dai, G., Qin, S., Wang, L., Wang, J., Yang, Z., Shu, Y., et al. (2015) Bevacizumab plus Capecitabine and Cisplatin in Chinese Patients with Inoperable Locally Advanced or Metastatic Gastric or Gastroesophageal Junction Cancer: Randomized, Double-Blind, Phase III Study (AVATAR Study). Gastric Cancer, 18, 168-176. http://dx.doi.org/10.1007/s10120-014-0351-5

[48] Wilke, H., Muro, K., Van Cutsem, E., Oh, S.C., Bodoky, G. and Shimada, Y. (2014) Ramucirumab plus Paclitaxel versus Placebo plus Paclitaxel in Patients with Previously Treated Advanced Gastric or Gastro-Oesophageal Junction Adenocarcinoma (RAINBOW): A Double-Blind, Randomised Phase 3 Trial. The Lancet Oncology, 15, 1224-1235. http://dx.doi.org/10.1016/S1470-2045(14)70420-6

[49] Fuchs, C.S., Tomasek, J., Yong, C.J., Dumitru, F., Passalacqua, R. and Goswami, C. (2014) Ramucirumab Monotherapy for Previously Treated Advanced Gastric or Gastro-Oesophageal Junction Adenocarcinoma (REGARD): An International, Randomised, Multicentre, Placebo-Controlled, Phase 3 Trial. The Lancet, 383, 31-39. http://dx.doi.org/10.1016/S0140-6736(13)61719-5

[50] Ohtsu, A., Ajani, J.A., Bai, Y.X., Bang, Y.J., Chung, H.C., Pan, H.M., Sahmoud, T., Shen, L., Yeh, K.H., Chin, K., et al. (2013) Everolimus for Previously Treated Advanced Gastric Cancer: Results of the Randomized, Double-Blind, Phase III GRANITE-1 Study. Journal of Clinical Oncology, 31, 3935-3943. http://dx.doi.org/10.1200/JCO.2012.48.3552

[51] Iveson, T., Donehower, R.C., Davidenko, I., Tjulandin, S., Deptala, A., Harrison, M., Nirni, S., Lakshmaiah, K., Thomas, A., Yiang, Y., et al. (2014) Rilotumumab in Combination with Epirubicin, Cisplatin, and Capecitabine as First-Line Treatment for Gastric or Oesophagogastric Junction Adenocarcinoma: An Open-Label, Dose De-Escalation Phase 1b Study and a Double-Blind, Randomised Phase 2 Study. The Lancet Oncology, 15, 1007-1018. http://dx.doi.org/10.1016/S1470-2045(14)70023-3

[52] Chau, I., Norman, A.R., Cunningham, D., Waters, J.S., Oates, J. and Ross, P.J. (2004) Multivariate Prognostic Factor Analysis in Locally Advanced and Metastatic Esophago-Gastric Cancer-Pooled Analysis from Three Multicenter, Randomized, Controlled Trials Using Individual Patient Data. Journal of Clinical Oncology, 22, 2395-2403. http://dx.doi.org/10.1200/JCO.2004.08.154

[53] Chau, I., Ashley, S. and Cunningham, D. (2009) Validation of the Royal Marsden Hospital Prognostic Index in Advanced Esophagogastric Cancer Using Individual Patient Data from the REAL 2 Study. Journal of Clinical Oncology, 27, e3-e4.

[54] Polee, M.B., Hop, W.C., Kok, T.C., Eskens, F.A., van der Burg, M.E., Splinter, T.A., Siersema, P.D., Tilanus, H.W., Stoter, G. and van der Gaast, A. (2003) Prognostic Factors for Survival in Patients with Advanced Esophageal Cancer Treated with Cisplatin-Based Combination Chemotherapy. British Journal of Cancer, 89, 2045-2050. http://dx.doi.org/10.1038/sj.bjc.6601364

[55] Kim, J.G., Ryoo, B.Y., Park, Y.H., Kim, B.S., Kim, T.Y., Im, Y.H. and Kang, Y.K. (2008) Prognostic Factors for Survival of Patients with Advanced Gastric Cancer Treated with Cisplatin-Based Chemotherapy. Cancer Chemotherapy and Pharmacology, 61, 301-307. http://dx.doi.org/10.1007/s00280-007-0476-x

[56] Lee, J., Lim, T., Uhm, J.E., Park, K.W., Park, S.H., Lee, S.C., Park, J.O., Lim, H.Y., Sohn, T.S., et al. (2007) Prognostic Model to Predict Survival Following First-Line Chemotherapy in Patients with Metastatic Gastric Adenocarcinoma. Annals of Oncology, 18, 886-891. http://dx.doi.org/10.1093/annonc/mdl501

[57] Vicente Conesa, M.A., Faez, L., Garrido, M., Custodio, A., López, C., Visa, L., Visa, L., Gallego, J., Fernandez, S., Ramchandani, A., et al. (2014) Prognostic Evaluation of a Multicenter Cohort of 484 Patients with Metastatic Gastroesophageal Adenocarcinoma. Annals of Oncology, 25, iv210-iv253. 